\title{
Immunomodulators: Friends or Enemies in Surgery for Crohns Disease?
}

Kalle Landerholm, Thordis Disa Kalman, Conny Wallon and Pär Myrelid

The self-archived postprint version of this journal article is available at Linköping University Institutional Repository (DiVA):

http://urn.kb.se/resolve?urn=urn:nbn:se:liu:diva-161226

N.B.: When citing this work, cite the original publication.

Landerholm, K., Kalman, T. D., Wallon, C., Myrelid, P., (2019), Immunomodulators: Friends or Enemies in Surgery for Crohns Disease?, Current Drug Targets, 20(13), 1384-1398.

https://doi.org/10.2174/1389450120666190617163919

Original publication available at:

https://doi.org/10.2174/1389450120666190617163919

Copyright: Bentham Science Publishers

http://www.benthamscience.com/ 


\section{Immunomodulators: friends or enemies in surgery for Crohn's disease?}

Kalle Landerholm ${ }^{1} \mathrm{MD}, \mathrm{PhD}$, Disa Kalman ${ }^{2}, \mathrm{MD}$, Conny Wallon ${ }^{2}, \mathrm{MD}$, PhD, Pär Myrelid ${ }^{2}$, $\mathrm{MD}, \mathrm{PhD}$

${ }^{1}$ Department of Clinical and Experimental Medicine, Linköping University and Department of Surgery, Ryhov Hospital, Jönköping, Sweden, ${ }^{2}$ Department of Clinical and Experimental Medicine, Linköping University and Department of Surgery, County Council of Östergötland, Linköping, Sweden

\section{Correspondence: $\quad$ Pär Myrelid}

Address: $\quad$ Department of Surgery, Linköping University Hospital, 58185 Linköping, Sweden.

Email: $\quad$ par.myrelid@liu.se

Phone: $\quad$ +46-10-1031581, +46-70-6849994

Disclosures: $\quad$ We declare that there was no conflict of interests during this research performance. 


\begin{abstract}
Crohn's disease is characterized by discontinuous transmural inflammation involving any portion of the gastrointestinal tract and may have a severe impact on quality of life. As it is a chronic disease it needs surgery and medicine as complementary therapies aimed at maintenance of remission and to prevent relapsing of symptoms and need of further surgery. Surgery in Crohn's disease is often performed in patients with a number of wellknown risk factors of post-operative complications, especially intra-abdominal septic complications. This review will look at the current knowledge of immunomodulating therapies in the peri-operative phase of Crohn's disease. The effect of immunomodulators in regards of post-operative complications is evaluated in clinical reports and compared with data from animal studies and the influence on wound healing. Further, the effect of immunomodulators on preventing, or at least postponing, primary as well as repeat surgery in Crohn's disease is reviewed in general or in selected high risk cohorts as well as the timing thereof.
\end{abstract}

\title{
Abbreviations
}

Anti-TNF Anti-Tumor Necrosis Factor

Aza Azathioprine

CD Crohn's Disease

CDAI Crohn's Disease Activity Index

$\mathrm{Cl} \quad$ Confidence Interval 
DSS Dextran Sulfate Sodium

IBD Inflammatory Bowel Disease

ICAM-1 Inter Cellular Adhesion Molecule-1

OR Odds Ratio

RCT Randomized Controlled Trial

TGF- $\beta \quad$ Transforming Growth Factor $\beta$

TNBS Trinitrobenzensulfonic acid

UC Ulcerative Colitis

5-ASA 5-Aminosalicylic acid

6-MP 6-Mercaptopurine 


\section{Introduction}

Crohn's disease (CD) is an inflammatory bowel disease (IBD) and characterized by discontinuous transmural inflammation involving any portion of the gastrointestinal tract, with the ileum and colon most commonly affected ${ }^{12}$. Symptoms are dominated by abdominal pain and obturations but diarrhoea and mucous in the stool, as well as fistulas, are quite frequent ${ }^{3-5}$. CD is sometimes associated with extra intestinal manifestations like arthralgia, eye, skin and liver manifestations like primary sclerosing cholangitis ${ }^{36}$. There is quite often a time lag between symptoms and diagnosis in $C D$ and some have had symptoms for many years before the diagnosis is finally established ${ }^{7}$. There is as yet no gold standard diagnostics of $C D^{8}$ which remains a test of clinical skill depending on relevant patient history, attentive physical examination, judicious laboratory testing, and detailed review of radiographic, endoscopic, and pathologic data ${ }^{8}$.

The disease was first treated with extensive resection ${ }^{9}$, with the inherent risk of developing short bowel syndrome and intestinal failure ${ }^{1011}$. The extent of surgical resection has since repeatedly been shown to be of less importance for treatment outcome ${ }^{12-14}$, and today bowel-preserving techniques are preferred and where inflamed areas are often not surgically removed and short strictures may be treated by strictureplasty instead of resection ${ }^{15-18}$.

As $C D$ is a chronic disease with no definite cure it may have a severe impact on quality of life compared with the general population due to lack of energy, pain, diarrhea, malnutrition, perianal disease, ostomy-related concerns and the uncertain nature of disease in general ${ }^{19-}$ 21. Previous studies have shown that such impairment in quality of life is associated with disease activity rather than the disease itself or even the localization or behavior of the disease $2022-27$. The different therapies for $C D$ are focused on relief of symptoms and dealing with complications to the disease. In active disease, induction of remission can be achieved either through medical therapy or surgery. When patients have no or limited symptoms therapies are aimed at maintenance of remission and to prevent relapsing of symptoms and need of further surgery. It is important to remember that most patients spend most of their life in remission ${ }^{28}$ and that medical therapy and surgery used as complementary therapies can achieve remission with low symptomatic load in many patients ${ }^{29}{ }^{30}$. The correlation 
between remission and quality of life is strong, regardless if remission was achieved medically or surgically ${ }^{3132}$.

\section{Immunomodulators}

Thiopurines are anti-metabolites developed during the 1950's and consists of three different drugs, 6-mercaptopurine (6-MP), azathioprine (Aza), and 6-thioguanine. They were first introduced as chemotherapy for cancer but today they are widely used as immunomodulators after transplantation as well as treatment of inflammatory bowel disease ${ }^{33-37}$. In Crohn's disease thiopurines are used to treat active disease in the hope of inducing remission and may thereafter be used to maintain remission. They are also used as prophylaxis against disease progress either upfront or following surgery in order to prevent recurrence.

Azathioprine has been endoscopically shown to heal the mucosa of both ileitis and colitis in Crohn's disease ${ }^{38} 39$. The place of thiopurines as maintenance therapy in IBD is well established ${ }^{35} 36$ why they have been increasingly used over the years ${ }^{4041}$. Healing of mucosal lesions within one year after initiation of medical therapy have been found to predict a favourable five year outcome concerning the degree of inflammation, need for repeat steroids and resectional surgery ${ }^{42}$. A Cochrane review showed a number needed to treat of six for quiescent disease but also a steroid sparing effect with a number needed to treat of three ${ }^{37}$. The results of a study by Markowitz et al on children with newly diagnosed Crohn's disease were in favour of starting thiopurines earlier in the course of the disease ${ }^{43}$. There are several ongoing studies to verify this finding in adults as well ${ }^{44}$. A French study found a high relapsing risk of Crohn's disease if the thiopurine therapy was interrupted, thus suggesting the thiopurine therapy not to be withdrawn if once tolerated ${ }^{45}$.

However, approximately $15 \%$ of patients have to end their thiopurine therapy because of negative side effects ${ }^{46}$. Both 6-MP and Aza are pro-drugs that are activated in the body through extensive metabolism ${ }^{47}$. Measurements of thioguanine nucleotides have been attempted to monitor the use of thiopurines and find the optimal dosage but with limited value $^{46}$. There is however data in favour of phenotyping and/or genotyping the catabolic enzyme thiopurine S-methyltransferase (currently 23 genetic variants have been described) 
prior to thiopurine therapy is commenced in IBD to prevent severe haematotoxicity ${ }^{48-50}$. All intolerance is not dose-dependent and it seems that some patients not tolerating Aza do tolerate a switch to 6-MP or 6-thioganine ${ }^{46} 51$.

Other immunomodulators used with variable success in CD including methotrexate, mycophenolate mofetil, tacrolimus, and cyclosporine $A^{52-62}$, but are so far regarded as a third line therapies in patients intolerant to thiopurines ${ }^{63-65}$.

The risk for post-operative complications in $C D$ appears to be increased compared with colorectal surgery in general ${ }^{66-68}$. At least some of this risk increment owes to the fact that surgery in $C D$ by necessity often is performed in patients with a number of well-known risk factors such as previous surgery, preoperative malnutrition, intra-abdominal abscesses or fistulas, bowel obstruction, steroid treatment, and possibly immunomodulation ${ }^{69-74}$. A negative dose-response effect from preoperative steroid treatment on anastomotic complications is well established from a number of studies and in meta-analyses ${ }^{69-7375} 76$. Poor nutritional status or low preoperative serum albumin have been found in earlier reports to be risk factors for intra-abdominal septic complications ${ }^{69} 71$ together with anemia ${ }^{77}$ and emergency surgery ${ }^{78}$. Unsurprisingly, one of the factors most convincingly associated with post-operative intra-abdominal intra-abdominal septic complications in up to $25 \%$ is presence of preoperative intra-abdominal abscess or fistula ${ }^{69-717479-83}$. The risk for anastomotic complications has also been shown to increase with the number of identified preoperative risk factors raising from below $5 \%$ in CD patients without any identified risk factor, to $14-30 \%$ with one risk factor, $16-38 \%$ with two risk factors, and as high as $26-100 \%$ with three or four risk factors present ${ }^{69} 717479$.

Surgeons have long been concerned that immunomodulation with e.g. thiopurines may impair healing and could be another risk factor for anastomotic complications ${ }^{74}{ }^{84}$, through mechanisms of impaired healing of the anastomosis and wound. The potential effect by immunomodulators on the healing capacity after surgery could be multi-factorial, suggested mechanisms include decreased proliferation and increased apoptosis of epithelial cell as well as T-cell-mediated suppression of the inflammatory reaction leading to reduced collagen synthesis and wound strength ${ }^{85} 86$. The knowledge in this respect is however rather limited. Clinical reports on the use of immunomodulators in relation to surgery are often 
focused on postoperative septic complications in general and do not always distinguish between CD and ulcerative colitis (UC) patients ${ }^{72} 8788$.

This review will try to shed some light on the current knowledge of immunomodulators, with a focus on thiopurines, and their role in the peri-operative phase. Both advantages and disadvantages in the pre- and post-operative setting will be discussed.

\section{Medication prior to surgery}

\section{Immunomodulators effect on postponing primary surgery}

A key question when it comes to immunomodulators is whether they are able to slow down disease progression in $C D$ and thereby reduce the need of hospitalizations and the risk of surgery ${ }^{89-91}$.

In children and young adults $(n=1,595)$ the risk for surgery among $C D$ patients with thiopurine use $(n=787)$ was $15.3 \%$ after 5 years in comparison with $22.1 \%$ in those without thiopurines $(n=808)(\log -r a n k p=0.02)^{92}$. During the follow up of in mean 4.3 years the adjusted risk was higher among those on thiopurines ( $\mathrm{HR} 1.85,95 \% \mathrm{Cl}: 1.37-2.50$ ), but when comparing those with early use of thiopurines (within the first year of diagnosis) there was a risk reduction compared with patients starting thiopurines later than one year of $C D$ diagnosis (HR 0.61, 95\% Cl: 0.41-0.91).

In Australia Kariyawasam et al studied the use and effects of thiopurines, and to some extent methotrexate ( $16 \%$ of those on immunomodulating therapy), in 1,035 CD patients at a tertiary referral center from 1970 to $2009^{93}$. The use of thiopurines increased from $12.0 \%$ to $54.3 \%$ over time $(p<0.0001)$ and the use within the first year increased from $1.3 \%$ to $35.8 \%$ ( $p<0.0001)$. Immunomodultors started within the first three years of diagnosis was associated with a lower risk of first abdominal surgery (HR $0.45,95 \% \mathrm{Cl}: 0.32-0.63$ ) or perianal surgery (HR 0.30, 95\% $\mathrm{Cl}: 0.16-0.56)^{93}$ in multivariable analysis. A similar pattern was seen in 506 incident CD patients from Hungary where the 1- and 5-year probability of thiopurine use increased from $3.2 \%$ and $6.2 \%$ to $34.8 \%$ and $46.2 \%$ between 1977 and $2008^{94}$. Using the same definition of early use as the Australian report, they found a lower 
risk of first intestinal surgery in patients with early immunomodulation compared to patients without thiopurines within the first three years (HR $0.43,95 \% \mathrm{Cl}: 0.28-0.65)^{94}$.

An English study including 5,640 CD patients by Chatu et al showed that the 5-year probability of being treated with thiopurines increased from $12 \%$ to $25 \%$ during the time period 1989-2005 $(p<0.0001)^{95}$. The 5-year risk of first intestinal resection in the same report was $7 \%$ in patients with $>12$ months of thiopurine use compared with $12 \%$ in those without or $<12$ months of thiopurines $(p<0.001)$, and in a Cox regression analysis giving a HR 0.31 (95\% Cl: 0.22-0.22) while early treatment (within the first year) had a comparable impact as late initiation of thiopurines ${ }^{95}$. Similar findings was reported from Cardiff by Ramadas et al, who found a significant increase in the use of early thiopurines (within first year of diagnosis), ranging from $3 \%$ in $1986-1991$ to $25 \%$ in $1998-2003^{96}$ coinciding with less CD related surgery, decreasing from $59 \%$ to $25 \%$ after five years for the same time periods and with a multivariable Cox regression thiopurines within the first year of diagnosis found a HR $0.47(95 \% \mathrm{Cl}: 0.27-0.79)^{96}$. This was not confirmed by Qiu et al who found no signs of effect on disease progression or need for surgery in patients with early thiopurine therapy in comparison with conventional management ${ }^{97}$. The same group found a greater chance of long term (after 36 months) endoscopic remission in patients on thiopurines with an endoscopic response after 12 months of initiated therapy, but once again no effect regarding need of surgery ${ }^{98}$.

In patients with late onset $C D(n=1,349)$ the risk of resectional surgery was not reduced among the $16.4 \%$ of patients who started thiopurine treatment during follow up. The time from diagnosis to start of thiopurines was 18.2 months and no effect was seen regardless if thiopurines were used for more or less than 12 months (mean duration of 33.9 months) ${ }^{99}$.

A French open label randomized controlled trial (RCT) on early use of thiopurines (within six months of $C D$ diagnosis) found a lower risk of perianal surgery after 3 years; $3 \%$ in the active group compared with $13 \%$ in the control group $(p=0.04)^{100}$, similar to the finding by Kariyawasam et $a l^{93}$. No such effect was found for intestinal surgery ( $8 \%$ vs $6 \%$ ) although this was difficult to interpret as both temporary stomas and closure thereof were included. Similarly Panes et al found no gain from early thiopurine use in newly diagnosed CD in terms 
of time in steroid free remission, but this study was under powered for disease progression and $C D$ related surgery ${ }^{101}$.

A review and meta-analysis covering $12,586 \mathrm{CD}$ patients found a $40 \%$ risk reduction of surgery in patients treated with thiopurines ( $\mathrm{HR} 0.59,95 \% \mathrm{Cl}: 0.48-0.73)^{91}$. The authors concluded that thiopurines are associated with a risk reduction of first surgery in CD but it is unclear if this is a true reduction or merely a postponing effect. Nor was it possible to adjust for factors like concomitant use of anti-TNF therapy and dose and timing of thiopurine therapy, in regards of time lag from diagnosis to start of treatment as well as time on thiopurines ${ }^{102}$. In a Portuguese study on $736 \mathrm{CD}$ patients thiopurines as mono-therapy, as well as in combination with anti-TNF, were associated with a decreased risk of disease progression, HR 0.15 (95\% Cl: 0.11-0.20) and HR 0.33 (95\% Cl: 0.21-0.51) respectively. The authors also found an association between an earlier disease progression with a longer delay to initiation of thiopurine treatment as well as shorter duration of treatment ${ }^{103}$

Interestingly a recent meta-analysis showed a small but significant risk reduction for developing colorectal cancer in IBD patients treated with thiopurines, especially in high risk individuals like long standing disease and extensive colitis ${ }^{104}$.

Despite what seems to be some benefit of early thiopurine therapy in $C D$, some question whether at least in some cases the bowel damage is too advanced already at the time of diagnosis and therefore thiopurines are given too late and maybe not for long enough ${ }^{105}$. This may especially be true for ileocaecal CD which carries the highest risk of surgery 96106107. In recent years two randomized controlled trials have compared medical therapy with surgery in ileocaecal $C D^{108}{ }^{109}$. The first trial compared thiopurines with ileocaecal resection ${ }^{108}$ and the second infliximab with laparoscopic primary resection ${ }^{109}$. Neither found any differences in quality of life during follow up but in the LIR!C-trial an important finding was that more than a third of patients starting infliximab treatment required ileocaecal resection during follow up, while in the same time frame only one in four patients with a primary resection was started on anti-TNF ${ }^{109}$.

One major concern with early initiation of immunomodulators or biologics is that by postponing surgery, patients tend to have developed more complex disease at the time of 
surgery which may be associated with a risk of more extensive resections and postoperative complications. The latter question is so far unanswered but there are some worrying reports concerning the first questions. An American register study looked at the surgical effects during a time period of increasing use of immunomodulators as well as anti-TNF, 1993$2004^{106}$. Despite lack of data on used medication they found a time trend towards less colonic and rectal resections in $\mathrm{CD}$ patients but with no effect on ileocaecal resection and a very worrisome increase by $60 \%$ in enteric fistulas from the small bowel $(p=0.04)$ from the beginning to the end of the study period ${ }^{106}$. An increasing frequency of multiple drugs used prior to surgery between 1992 and 2009 was confirmed in a German study ${ }^{110}$. During the same time period an increasing percentage of patients came to surgery with clinical deterioration including weight-loss and multiple structures involved in inflammatory masses contributing to more frequent use of stomas yet more intra-abdominal septic complications, ranging from $7 \%$ at the beginning to $36 \%$ at the end. These changes may not be caused by the more aggressive therapies in themselves but rather the timing of surgery and puts focus on the importance of a very close collaboration between gastroenterologists and colorectal surgeons within the field of $C D^{111} 112$.

\section{Postoperative complications after preoperative use of immunomodulators}

Possible reasons for an impaired anastomotic healing with immunomodulation with thiopurines include T-cell-mediated suppression, decreased proliferation and increased apoptosis of epithelial cells ${ }^{85}{ }^{86}$. At the same time thiopurines have a steroid sparing effect ${ }^{113}$ and the adverse effect of steroids on wound healing might be of greater importance than a possible adverse effect of immunomodulators like thiopurines ${ }^{70-72} 79$.

There are a number of reports regarding the effect of thiopurines on postoperative recovery and outcome. Most of them are either on a mixture of IBD patients with UC and CD, with concomitant corticosteroid therapy or complications not separated into anastomotic complications and general infectious complications 728788114115 .

\section{Human data}


At our own institution we evaluated the outcome in 343 consecutive operations for CD including a primary anastomosis ${ }^{74}$. Intra-abdominal septic complications occurred in $8 \%$ and re-intervention within 30 days was required in $10 \%$ of the operations. Patients preoperatively treated with thiopurines had an increased risk of postoperative anastomotic complications compared to patients without such treatment ( $16 \%$ vs. $6 \%(p=0.044))$. Likewise, the rate of surgical re-intervention was increased from $9 \%$ to $20 \%$ in patients on thiopurine treatment $(p=0.016)$. Other independent risk factors in logistic regression analysis were colo-colonic anastomosis and presence of intra-abdominal fistula/abscess prior to surgery ${ }^{70}$.

Aberra et al retrospectively studied 159 patients with UC or $C D$, with elective abdominal surgery, with or without anastomosis, excluding all patients with pre-operative intraabdominal septic complications and pyogenic complications of the disease ${ }^{72}$. The rate of major infectious complications was $20 \%$ for steroid treated patients, $12 \%$ for thiopurines with $(n=34)$ or without $(n=18)$ steroids, and $4 \%$ for those without any of these treatments $(n=51)$. Although the difference was not statistically significant, the rates are similar to our own report ${ }^{79}$. However, the complications were analyzed according to minor (urinary tract infection and temperature $>38.6^{\circ} \mathrm{C}$ ) or major complications (e.g. wound infection, sepsis, pneumonia, peritonitis, abdominal abscess, and wound dehiscence) and not specified for postoperative intra-abdominal septic complications, by far the most feared complication.

In another study by Colombel et al of 270 CD patients, $26 \%$ received a stoma and $74 \%$ received stricturoplasty or one or more anastomoses ${ }^{87}$. In that study, there was an obvious risk for selection bias when later analyzing all of the patients together, since high-risk patients were more likely to receive a stoma. No adverse effect was seen in the group receiving immunomodulators, but most of the patients were treated with steroids and only eight patients $(3 \%)$ received immunomodulators alone and 33 patients (12\%) received no medication prior to surgery. Furthermore, some of the patients received their immunomodulating therapy for less than two weeks prior to surgery, a time period that probably is too short to cause any negative effect ${ }^{116}$. At the same time patients who terminated their immunomodulation as late as four weeks prior to surgery were coded as not being on immunomodulation, a questionably short wash out period. Another issue with 
this report is that anastomotic dehiscences (5\%) were included in a larger group of septic complications together with e.g. wound infection, pneumonia, sepsis, bacteremia, and anastomotic complications and not analyzed alone.

The results of a study by Tay et al were in favour of improved perioperative outcome for patients with preoperative immunomodulation in 100 studied patients with CD going through primary surgery with anastomosis or strictureplasty ${ }^{114}$. Immunomodulators were analyzed together with biologics and further data regarding medications as well as the patients are limited in the report making it hard to evaluate. A more recent report from Japan found no influence of thiopurines on the surgical outcome, but numbers are small ${ }^{117}$.

In a report from the Mayo Clinic on ileal pouch anal-anastomoses in UC, rather than $C D$, an increased risk of infectious complications (anastomotic leak, pelvic abscess, or wound infection) were seen in patients pre-operatively treated with thiopurines in a univariate analysis (odds ratio=2.1; $95 \% \mathrm{Cl}, 1.1-4.3$ ), but not after a multiple variable logistic regression analysis (odds ratio=1.3; $95 \% \mathrm{Cl}, 0.6-2.9){ }^{115}$. Mahadevan et al studied the early outcome of ileal pouch-anal anastomosis in 209 patients with UC ${ }^{88}$. Sixteen percent $(9 / 55)$ of the patients on thiopurines had their immunomodulating therapy withdrawn as late as one week before surgery and were coded as not on immunomodulation. Among the remaining 46 patients with thiopurines, the rate of anastomotic complication was $9 \%$ compared with $6 \%$ in those without thiopurines (not significantly different). In their study, high-dose steroids and severe or fulminant disease according to Truelove-Witt criteria correlated with an increased risk of anastomotic complications $(p<0.01)$. These studies on UC patients may also speak in favor of poor surgical timing rather than medication as only patients with ongoing colitis would be in need of immunomodulators and in these cases a staged procedure is proposed ${ }^{118}$.

One major concern with all these studies is the substantial risk of selection bias as they are not really comparing patients with or without immunomodulation but rather two separate cohorts of patients; one with milder disease and one with more severe disease. Patients with more advanced Crohn's disease are obviously more likely to receive aggressive therapy, but also more prone to suffer surgical complications. One factor supporting this line of thinking is the increasing number of patients receiving immunomodulators over time 709596 . 
A plausible explanation for this would be that the most severe patients are treated at an earlier stage with "new" drugs, may it be thiopurines, anti-TNF or vedolizumab and as care providers become more "at ease" with these therapies they spread to a broader population of $C D$ patients. In our report thiopurine therapy in patients going through primary surgery was $4 \%$ compared to $19 \%$ among those operated before $(p<0.001)$ and treatment prior to surgery increased from $9 \%$ during the first seven years of the study period to $19 \%$ during the subsequent seven-year period $(p=0.01)^{74}$.

\section{Animal models}

Animal models are far from surgery in severly ill, real-life patients, yet there are things we can learn from them. In the case of corticosteroids they have an adverse effect on the healing of bowel anastomoses, both in regards of obvious leaks as well as decreased bursting pressures ${ }^{119-122}$. A possible reason for this effect is inhibition of collagen synthesis through blocking of transforming growth factor $\beta$ (TGF- $\beta$ ) and/or intercellular adhesion molecule-1 (ICAM-1)119 120123124 .

Azathioprine was tested in bronchial anastomoses and skin wounds on dogs by Lima et al who found that the breaking strength was at least halved in dogs treated with a combination of prednisolone $(2 \mathrm{mg} / \mathrm{kg})$ and azathioprine $(1.5 \mathrm{mg} / \mathrm{kg})$ compared to controls $^{125}$. In a study from our own group C57BL6 mice were randomly divided into two groups, with or without dextran sulfate sodium (DSS) induced colitis ${ }^{126}$. The two groups were then further randomly divided into four groups each, receiving placebo, prednisolone ( $2 \mathrm{mg} / \mathrm{kg}$ bodyweight), azathioprine ( $5 \mathrm{mg} / \mathrm{kg}$ bodyweight) or infliximab ( $5 \mathrm{mg} / \mathrm{kg}$ bodyweight) during 14 days before surgery with a colo-colonic anastomosis. Bursting pressures were assessed two days later as a measure of anastomotic healing, and was found to be decreased in the prednisolone groups compared to all of the other three groups. There were no other significant differences between the groups, including azathioprine compared to placebo. Stolzenburg et al, who tested the anastomotic healing in rats using breaking strength, used up to four times as high dose of azathioprine as in the previous study but without any adverse effect on the breaking strength ${ }^{127}$. 
The use of tacrolimus has only been tested in two studies; in both cases confirming a detrimental effect on dermal healing ${ }^{128}{ }^{129}$. However, one of the studies also examined the bursting pressure in colonic anastomoses and found no influence of tacrolimus in comparison with controls ${ }^{128}$.

Cyclosporine A has only been evaluated through breaking strength of dermal incisions in rats and was found to impair the breaking strength and accumulation of collagen in the wound compared to controls ${ }^{130131}$.

Mycophenolate mofetil has been studied in colonic anastomoses on rats with up to $40 \%$ reduction of the bursting pressure ${ }^{132}$. No effect was however seen on the synthesis of collagen in contrast to the effect of steroids. Instead, a decrease in acidic mucins was seen in mycophenolate mofetil treated animals, postulating a possible diminished protection of the healing process from luminal pathogens ${ }^{132}$. An interesting finding on the association between anastomotic healing and acidic mucins is the report by Egger et $a{ }^{133}$. They administered keratinocyte growth factor to rats and found that bursting pressures were raised by $19-49 \%$ during the first seven days postoperatively $(p<0.05)$. At the same time an increase of the colonic crypt depth and acidic mucin content at the anastomosis $(p<0.05)$ was found but no difference in collagen deposition, promoting a possible role by the mucus in protecting the healing of a colonic anastomosis. Moreover, keratinocyte growth factor has been found to ameliorate the inflammation in DSS induced colitis in mice as well as trinitrobenzensulfonic acid (TNBS) induced colitis in rats ${ }^{134} 135$.

In animal models broad inhibition of matrix metalloproteinases have shown an ameliorating effect on TNBS induced colitis ${ }^{136} 137$. Further, such inhibition has shown increased bursting pressure by $28-48 \%$ in colonic anastomoses on rats ${ }^{138} 139$ opening up an interesting field in regards of anti-inflammatory therapy as well as attempts of decreasing the surgical risks in CD. In the previously mentioned study from our own unit no signs were seen favoring an improvement of the bursting pressure by any of the anti-inflammatory therapies given compared with placebo ${ }^{126}$.

\section{The value of measuring or tapering drugs prior to surgery}


The knowledge of how long the sustainability of the thiopurine effect is after withdrawal is scarce. In some studies six weeks were used as a pragmatic drug-free period prior to surgery as it is the time period possible to use clinically similar to the tapering of steroids ${ }^{74}$ ${ }^{140}$. Further, in evaluating the thiopurine therapy it should probably have been ongoing for at least three months as it acts slowly and a possible clinical effect can be evaluated approximately $\geq 17$ weeks after induction of remission in active disease ${ }^{116}$.

The most important issue in this regard is probably less exact cut off values but rather to have a good pre-surgical evaluation trying to diminish all possible risk factors ${ }^{69} 717479$. Patients that are well optimized preoperatively are more likely to have a primary anastomosis without too much risk-taking ${ }^{141}$ whereas for patients who need under less fortunate circumstances a temporary double barrel stoma, often closed after a few months of recovery is the safer alternative ${ }^{142}$.

\section{Postoperative recurrence of Crohn's disease}

In historical studies, approximately $75 \%$ of CD patients underwent abdominal surgery at least once during their lifetime ${ }^{143}{ }^{144}$. The introduction of immunomodulators appeared not to have decreased the need for surgery up until the new millenium ${ }^{40}$. More recent data suggest that surgery may now be less frequent, possibly owing to medical treatment with immunomodulators and biologicals. In a population-based Danish study $29 \%$ of newly diagnosed CD patients had undergone abdominal surgery within 7 years ${ }^{145}$. Surgery is however not curative for $C D$ which may recur anywhere in the gastrointestinal tract but typically in, or just proximal to, previous anastomoses or strictureplasties ${ }^{146147}$.

Endoscopic recurrence is apparent in a majority of patients already within the first year after resectional surgery for $\mathrm{CD}^{148}$. Patients receiving placebo treatment in recent trials had severe endoscopic recurrence in $35 \%$ after 6 months $^{149}, 58 \%$ after 1 year ${ }^{150}, 78 \%$ after 1 year ${ }^{151}, 50 \%$ after 18 months $^{152}$ and $64 \%$ after 2 years ${ }^{153}$. The severity of endoscopic recurrence is generally graded according Rutgeerts' score ${ }^{154}$. Endoscopic recurrence is associated with later clinical recurrence ${ }^{146} 154$ but many patients with endoscopic recurrence 
remain asymptomatic, and the same applies to patients with a radiological recurrence. Symptomatic or clinical recurrence occurs in $20-40 \%$ within the first year after surgery in the placebo arms of most clinical trials ${ }^{148}$. Hanauer et al reported clinical recurrence in as many as $77 \%$ within 2 years ${ }^{153}$; whereas two other trials found clinical recurrence in $23 \%{ }^{155}$ and $45 \%{ }^{156}$ after 3 years. An observational population-based cohort study of patients diagnosed with CD before 1989 reported clinical recurrence after surgery in $44 \%$ after 10 years $^{143}$.

Surgical recurrence, i.e. recurrent disease requiring repeat surgery, occurred in $20-44 \%$ within 10 years after intestinal resection in older cohort studies ${ }^{157} 158$. More recently VesterAndersen et al found that $29 \%$ of patients in Copenhagen operated for Crohn's disease had a second resection within 5 years ${ }^{145}$, other cohort studies including patients with prophylaxis found surgical recurrence in up to $50 \%^{147} 159-162$.

The number one risk factor for postoperative recurrence of $C D$ is smoking ${ }^{161}{ }^{163-165}$. A metaanalysis found a twofold increased risk of clinical recurrence and a 2.5 -fold increase in surgical recurrence in smokers ${ }^{166}$. Other patient-related factors such as age and gender has not convincingly been associated with the risk of recurrence ${ }^{167168}$. Penetrating disease $\mathrm{e}^{163169}$, shorter duration of Crohn's disease before surgery ${ }^{161} 167$ and repeat surgery ${ }^{168}$ all appear to be associated with an increased risk of recurrence. Disease location on the other hand does not obviously affect the recurrence rate, although coexistent peri-anal disease is associated with worse postoperative outcome ${ }^{167168}$. Histopathological factors such as presence of granulomas ${ }^{170}$ and myenteric plexitis have also been associated with a higher risk of postoperative recurrence ${ }^{171} 172$. Strictureplasties may be associated with higher risk of recurrence than resection ${ }^{173} 174$.

With the exception of smoking habits, most of the established risk factors for postoperative recurrence cannot easily be influenced and several of them are in reality surrogate markers of aggressive or advanced disease.

Against this background, a key question is how to best avoid or defer recurrence and what place medical prophylaxis should have. Should all patients receive prophylactic drugs after resection for $C D$, or only patients at higher risk of recurrence? Is prophylaxis better started 
immediately or when there is evidence of e.g. endoscopic recurrence? Which drug should be used?

\section{Effectivenss of immunomodulators as prophylaxis against postoperative recurrence}

A number of observational, mostly retrospective cohort studies have indicated that thiopurine analogues protect against postoperative recurrence $e^{147159-162175}$. This review will however focus on the currently available randomized controlled trials of the subject.

6-mercaptopurin was compared to 5-ASA and placebo in a multicentre RCT including 131 patients with ileocolonic resection and anastomosis ${ }^{153} .6-\mathrm{MP}$ had a moderate and statistically significant effect on the risk of clinical recurrence within 24 months, which affected 50\% (95\% Cl 34-68\%) with 6-MP compared to 77\% (61-91\%) in the placebo group (HR 0.52). The risk of endoscopic recurrence was also reduced in the 6-MP group to $43 \%$ compared to $64 \%$ in the placebo group (HR 0.48). 5-ASA did not reach statistically significant superiority to placebo in any aspect.

Ardizzone et al randomized RCT 142 patients to receive either 5-ASA or azathioprine for postoperative prophylaxis after resection or strictureplasty for stricturing $C^{176}$. At 24 months after surgery there was a trend towards less clinical as well as surgical relapses with azathioprine, but no statistically significant difference was found.

Herfarth et al briefly reported their RCT comparing 5-ASA and azathioprine ${ }^{177}$. The study was stopped prematurely when an interim analysis made it clear that the hypothesis of superiority of AZA versus 5-ASA could not be tested with the planned sample size. Only 37 patients received treatment for a full year and treatment failure defined as clinical or severe endoscopic recurrence did not differ between the groups (9/18 with azathioprine vs. 9/19 with 5-ASA).

In another RCT, 81 patients with ileal or ileocolonic resection and anastomosis received in addition to metronidazole either azathioprine or placebo ${ }^{151}$. The risk of severe endoscopic 
recurrence within 12 months was statistically significantly lower among patients on azathioprine by both intention-to-treat ( 55 vs. $78 \%$ ) and per protocol (44 vs. $69 \%$ ) analyses.

Peyrin-Biroulet et al performed a meta-analysis in 2009 including the four available randomized trials at the time ${ }^{178}$ and concluded that prophylaxis with azathioprine and 6-MP is associated with a modest reduction (8-15\%) in clinical recurrence compared to control groups receiving placebo, 5-ASA or metronidazole within the first postoperative year.

Reinisch et al interestingly included 78 patients operated for CD 6-24 months earlier with at least moderate endoscopic recurrence but without clinical recurrence $(\text { CDAl }<200)^{179}$. Patients were randomized to receive either azathioprine or 5-ASA treatment, and the primary endpoint was treatment failure defined by worsened CDAl score or study drug discontinuation at 12 months. Clinical recurrence was significantly lower with azathioprine but at the same time discontinuation due to adverse events was significantly higher, and the frequency of treatment failure therefore did not differ between azathioprine and 5-ASA.

Savarino et al randomized 51 patients post resection for ileal or ileocolonic CD to receive adalimumab, azathioprine or 5-ASA ${ }^{180}$. Although each group was small, the risks of endoscopic and clinical recurrence at 24 months were dramatically lower for patients receiving adalimumab with. Outcomes did not differ significantly between patients treated with azathioprine and 5-ASA.

In another Italian RCT, 22 patients operated with ileocolonic resection and considered to be at high risk of recurrence due to having at least two risk factors were randomized to infliximab or azathioprine prophylactic treatment ${ }^{181}$. As the trial was small, with no sample size calculation and un-blinded it was presented as a pilot study and the results should be interpreted with precaution. The primary endpoints endoscopic or clinical recurrence at 12 months did not differ significantly between the groups.

The above mentioned seven RCTs were all included in a 2014 Cochrane systematic review concluding that purine analogues may be superior to placebo for maintenance of surgically induced remission of $C D$ but that the quality of evidence for this was low ${ }^{182}$. The relative efficacy of purine analogues to 5-ASA was uncertain due to conflicting results. The two trials 
comparing azathioprine to infliximab or adalimumab indicate that adalimumab may be superior to azathioprine but the overall evidence level was considered to be very low.

The most comprehensive trial so far included 240 patients post ileocolonic or small bowel resection who were randomized to either azathioprine or placebo ${ }^{155}$. The primary endpoint of the TOPPIC study was clinical recurrence within 3 years, occurring in $13 \%$ of patients receiving azathioprine and in $23 \%$ of patients given placebo (adjusted HR 0.54 ( $95 \% \mathrm{Cl} 0.27-$ 1.06)). Most interestingly the protective effect was very pronounced among smokers (HR $0.13(0.04-0.46))$, whereas no protective effect at all was seen among non-smokers.

A recent RCT compared azathioprine with adalimumab in 81 patients and found no difference in endoscopic, radiological, clinical or surgical recurrence within the first year ${ }^{183}$.

Data from pediatric cohorts are very limited both in number of studies as well as size of the studies and not further discussed in this review ${ }^{184-186}$.

In summary, there seems to be a modest protective effect from thiopurines against postoperative recurrence in CD. Most interestingly, the hitherto largest RCT (TOPPIC) suggested that this effect is completely explained by a dramatically reduced risk of recurrence among smokers, whereas non-smokers may not benefit from prophylaxis at all ${ }^{155}$. No other drug including anti-TNF has convincingly proved superior to thiopurines for prophylaxis in $C D$.

\section{Timing of prophylaxis}

A retrospective study included 199 patients with ileocaecal resection for CD given immediate postoperative prophylaxis, tailored prophylaxis when endoscopic recurrence was confirmed, or no prophylaxis ${ }^{187}$. The prophylaxis could be either antibiotics, mesalamine, thiopurines or anti-TNF. The HR for clinical recurrence in multivariable analysis was similar between tailored and immediate prophylaxis, but also with no prophylaxis at all. The 
retrospective design and the associated risk of bias, as well as the multitude of studied drugs make the results difficult to interpret.

An attempt at avoiding these biases was made in an RCT including patients with resection and anastomosis for ileocolonic $\mathrm{CD}$ at four centres ${ }^{149}$. Patients were randomized to receive azathioprine immediately (systematic) or to undergo ileocolonscopy after 6 and 12 months and start azathioprine in case of endoscopic recurrence (Rutgeerts score $\geq 2$ ) (endoscopydriven). Endoscopic, radiological and clinical recurrence rates after 24 months were compared and no differences were found between systematic and endoscopy-driven prophylaxis. The study was stopped prematurely due to slow recruitment when only 63 patients had been included, compared to the intended sample size of nearly 250 patients. Again, this precludes any firm recommendations to be made.

The POCER trial was cleverly designed to study the optimal postoperative prophylaxis program and included $174 \mathrm{CD}$ patients post resection with an endoscopically accessible anastomosis at 17 centers in Australia and New Zeeland ${ }^{165}$. Patients at low risk of recurrence were given no prophylaxis to begin with, those at high risk were given azathioprine and those at high risk who did not tolerate azathioprine were given adalimumab. All patients were then randomized to either an active arm including a colonoscopy at 6 months with treatment step-up if an endoscopic recurrence was found, or to a control arm with no surveillance colonoscopy. The primary endpoint was endoscopic recurrence at an 18-month colonoscopy which was significantly lower with the active care. There was also a nonsignificant trend towards better clinical outcome in the active arm.

The most recent retrospective cohort study compared the risk of surgical recurrence with systematic, endoscopy-driven and symptomatic-driven postoperative prophylaxis using azathioprine ${ }^{188}$. The authors found that the risk of surgical recurrence was lower with either systematic or endoscopy-driven prophylaxis compared to azathioprine started upon clinical recurrence. However, this result will be biased by the fact that an unknown number of patients never had a clinical recurrence and thus the outcome for the larger group of patients who were given no prophylaxis until they had symptoms may be similar to those with systematic or endoscopy-driven prophylaxis. Nevertheless, the study does support 
endoscopy-driven over systematic prophylaxis as it will avoid azathioprine for some patients and delay treatment start in others with the same risk of surgical recurrence.

In summary, the available results cannot really answer whether upfront prophylaxis or treatment started when endoscopic recurrence is evident is superior to prevent clinical or surgical recurrence. Direct evidence for selective prophylaxis to high risk patients is also lacking. The POCER trial showed that active endoscopic monitoring leads to better outcome ${ }^{165}$.

\section{Adverse events and cost}

Thiopurines are known to cause a number of adverse events and previous cohort studies have indicated discontinuation rates between 9 and $39 \%{ }^{189}$. Discontinuation due to adverse events were also reported in the available RCTs and importantly most of these studies were blinded. The results were conflicting with higher discontinuation rate among patients receiving thiopurines than placebo or other control drugs in some 176177179183 but not in other studies 151153180181 . In the recent, large and double-blinded RCT comparing 6mercaptopurine with placebo adverse events were at least as common among patients receiving placebo ${ }^{155}$.

Studies of cost effectiveness of postoperative medical prophylaxis per se have shown conflicting results which is perhaps not very surprising given the uncertainty about the effectiveness of various drugs and regimens ${ }^{190} 191$.

\section{Conclusion}

Many of the reports on the possible adverse effects by thiopurines and other immunomodulators lack in quality and differ too much in outcomes in order to perform a high quality meta-analysis. Moreover, many of the patients are often receiving more than one type of medication which tarnishes the picture even further. To verify if 
immunomodulators and other modern anti-inflammatory therapies are interfering with the healing capacities or not require large randomized multi-center studies. One explanation to the different findings on the effect of these therapies may be that patients at one center are operated at a later stage of the disease compared with another center ${ }^{192}$. Thus these treatments may only act as surrogate markers for patients with a more severe illness, with an inherent healing disturbance or at least more prone to be associated with an increased risk of post-operative complications. Data speaking in this direction are the reports from Scarpa et al and Welsch et al where patients with CD suffering from postoperative complications had an increased risk of early surgical recurrences ${ }^{193}{ }^{194}$, warranting prophylactic thiopurine use according to the authors ${ }^{193}$. This increased risk of early relapsing of the disease after a surgical complication may be the other way around; the early relapse is a signal of an aggressive disease which is associated with an increased risk of postoperative complications.

In the post-operative phase the available evidence suggests that thiopurines provide modest protection against postoperative recurrence in $C D$, with fewer recurrences than patients treated with placebo or 5-ASA. It remains uncertain whether prophylaxis with antiTNF is more effective. Evidence for who should receive postoperative prophylaxis is also limited. Due to the mediocre effect, frequent adverse events and cost, most authors seem to agree that prophylaxis should not be started indiscriminately in all patients. The current ECCO guidelines recommend prophylaxis with thiopurines or anti-TNF to patients with at least one risk factor for recurrence ${ }^{168}$. Smoking is a major risk factor for recurrence and the TOPPIC trial found a dramatically reduced risk of recurrence from azathioprine in smokers $^{155}$. Therefore, smokers who cannot be convinced to stop certainly should be considered for prophylaxis. Another option is to monitor patients with repeat investigations and initiate prophylaxis when endoscopic or radiological recurrence develops. The rationale to start medication in asymptomatic patients is that the disease otherwise will progress and that treatment at that point will be less effective. The problem with an endoscopy-driven approach however, is the very high occurrence of early endoscopic recurrence and critics argue that it may not be very predictive of clinical recurrence after all ${ }^{195}$. 
Some authors have suggested a regimen with immediate postoperative prophylaxis with thiopurines to high risk patients combined with endoscopic surveillance for all and step-up treatment if the disease relapses ${ }^{167}$. Such an algorithm was studied in the POCER trial and the addition of endoscopic monitoring was found to reduce later endoscopic recurrence but again evidence of less clinical recurrence is lacking ${ }^{165}$. 


\section{References}

1. Podolsky DK. Inflammatory bowel disease. N Engl J Med 2002;347(6):417-29.

2. Vind I, Riis L, Jess T, et al. Increasing incidences of inflammatory bowel disease and decreasing surgery rates in Copenhagen City and County, 2003-2005: a populationbased study from the Danish Crohn colitis database. Am J Gastroenterol 2006;101(6):1274-82.

3. Lindgren A, Wallerstedt S, Olsson R. Prevalence of Crohn's disease and simultaneous occurrence of extraintestinal complications and cancer. An epidemiologic study in adults. Scand J Gastroenterol 1996;31(1):74-8.

4. Tang LY, Rawsthorne P, Bernstein CN. Are perineal and luminal fistulas associated in Crohn's disease? A population-based study. Clin Gastroenterol Hepatol 2006;4(9):1130-4.

5. Schwartz DA, Loftus EV, Jr., Tremaine WJ, et al. The natural history of fistulizing Crohn's disease in Olmsted County, Minnesota. Gastroenterology 2002;122(4):875-80.

6. Bernstein CN, Blanchard JF, Rawsthorne P, et al. The prevalence of extraintestinal diseases in inflammatory bowel disease: a population-based study. Am J Gastroenterol 2001;96(4):1116-22.

7. Pimentel M, Chang M, Chow EJ, et al. Identification of a prodromal period in Crohn's disease but not ulcerative colitis. Am J Gastroenterol 2000;95(12):3458-62.

8. Sands BE. From symptom to diagnosis: clinical distinctions among various forms of intestinal inflammation. Gastroenterology 2004;126(6):1518-32.

9. Keller J, Panter H, Layer P. Management of the short bowel syndrome after extensive small bowel resection. Best Pract Res Clin Gastroenterol 2004;18(5):977-92.

10. Agwunobi AO, Carlson GL, Anderson ID, et al. Mechanisms of intestinal failure in Crohn's disease. Dis Colon Rectum 2001;44(12):1834-7.

11. Thompson JS, Iyer KR, DiBaise JK, et al. Short bowel syndrome and Crohn's disease. $J$ Gastrointest Surg 2003;7(8):1069-72.

12. Fazio VW, Marchetti F, Church M, et al. Effect of resection margins on the recurrence of Crohn's disease in the small bowel. A randomized controlled trial. Ann Surg 1996;224(4):563-71.

13. Post S, Herfarth C, Bohm E, et al. The impact of disease pattern, surgical management, and individual surgeons on the risk for relaparotomy for recurrent Crohn's disease. Ann Surg 1996;223(3):253-60.

14. Raab Y, Bergström R, Ejerblad S, et al. Factors influencing recurrence in Crohn's disease. An analysis of a consecutive series of 353 patients treated with primary surgery. Dis Colon Rectum 1996;39(8):918-25.

15. Poggioli G, Pierangeli F, Laureti S, et al. Review article: indication and type of surgery in Crohn's disease. Aliment Pharmacol Ther 2002;16 Suppl 4:59-64.

16. Yamamoto T, Bain IM, Allan RN, et al. An audit of strictureplasty for small-bowel Crohn's disease. Dis Colon Rectum 1999;42(6):797-803.

17. Yamamoto T, Allan RN, Keighley MR. Long-term outcome of surgical management for diffuse jejunoileal Crohn's disease. Surgery 2001;129(1):96-102.

18. Yamamoto T, Fazio VW, Tekkis PP. Safety and efficacy of strictureplasty for Crohn's disease: a systematic review and meta-analysis. Dis Colon Rectum 2007;50(11):196886.

19. Bernklev T, Jahnsen J, Lygren I, et al. Health-related quality of life in patients with inflammatory bowel disease measured with the short form-36: psychometric 
assessments and a comparison with general population norms. Inflamm Bowel Dis 2005;11(10):909-18.

20. Canavan C, Abrams KR, Hawthorne B, et al. Long-term prognosis in Crohn's disease: factors that affect quality of life. Aliment Pharmacol Ther 2006;23(3):377-85.

21. Blondel-Kucharski F, Chircop C, Marquis P, et al. Health-related quality of life in Crohn's disease: a prospective longitudinal study in 231 patients. Am J Gastroenterol 2001;96(10):2915-20.

22. Casellas F, Vivancos JL, Sampedro M, et al. Relevance of the phenotypic characteristics of Crohn's disease in patient perception of health-related quality of life. Am J Gastroenterol 2005;100(12):2737-42.

23. Andersson P, Olaison G, Bendtsen P, et al. Health related quality of life in Crohn's proctocolitis does not differ from a general population when in remission. Colorectal Dis 2003;5(1):56-62.

24. Tillinger W, Mittermaier C, Lochs H, et al. Health-related quality of life in patients with Crohn's disease: influence of surgical operation--a prospective trial. Dig Dis Sci 1999;44(5):932-8.

25. Larsson K, Lööf L, Rönnblom A, et al. Quality of life for patients with exacerbation in inflammatory bowel disease and how they cope with disease activity. J Psychosom Res 2008;64(2):139-48.

26. Casellas F, Rodrigo L, Nino P, et al. Sustained improvement of health-related quality of life in Crohn's disease patients treated with infliximab and azathioprine for 4 years. Inflamm Bowel Dis 2007;13(11):1395-400. doi: 10.1002/ibd.20205

27. Casellas F, Lopez-Vivancos J, Badia X, et al. Influence of inflammatory bowel disease on different dimensions of quality of life. Eur J Gastroenterol Hepatol 2001;13(5):56772.

28. Silverstein MD, Loftus EV, Sandborn WJ, et al. Clinical course and costs of care for Crohn's disease: Markov model analysis of a population-based cohort. Gastroenterology 1999;117(1):49-57.

29. Andrews HA, Keighley MR, Alexander-Williams J, et al. Strategy for management of distal ileal Crohn's disease. Br J Surg 1991;78(6):679-82.

30. Andersson P, Olaison G, Bodemar G, et al. Low symptomatic load in Crohn's disease with surgery and medicine as complementary treatments. Scand J Gastroenterol 1998;33(4):423-29.

31. Casellas F, Lopez-Vivancos J, Badia X, et al. Impact of surgery for Crohn's disease on health-related quality of life. Am J Gastroenterol 2000;95(1):177-82.

32. Ponsioen CY, de Groof EJ, Eshuis EJ, et al. Laparoscopic ileocaecal resection versus infliximab for terminal ileitis in Crohn's disease: a randomised controlled, open-label, multicentre trial. Lancet Gastroenterol Hepatol 2017;2(11):785-92. doi: 10.1016/S2468-1253(17)30248-0

33. Rhodes J, Bainton D, Beck P. Azathioprine in Crohn's disease. Lancet 1970;2(7683):1142.

34. Fraser AG, Orchard TR, Jewell DP. The efficacy of azathioprine for the treatment of inflammatory bowel disease: a 30 year review. Gut 2002;50(4):485-9.

35. Pearson DC, May GR, Fick GH, et al. Azathioprine and 6-mercaptopurine in Crohn disease. A meta-analysis. Ann Intern Med 1995;123(2):132-42.

36. Korelitz BI, Adler DJ, Mendelsohn RA, et al. Long-term experience with 6mercaptopurine in the treatment of Crohn's disease. Am J Gastroenterol 1993;88(8):1198-205. 
37. Prefontaine E, Sutherland LR, Macdonald JK, et al. Azathioprine or 6-mercaptopurine for maintenance of remission in Crohn's disease. Cochrane Database Syst Rev 2009(1):CD000067.

38. D'Haens G, Geboes K, Ponette E, et al. Healing of severe recurrent ileitis with azathioprine therapy in patients with Crohn's disease [see comments]. Gastroenterology 1997;112(5):1475-81.

39. D'Haens G, Geboes K, Rutgeerts P. Endoscopic and histologic healing of Crohn's (ileo-) colitis with azathioprine. Gastrointest Endosc 1999;50(5):667-71.

40. Cosnes J, Nion-Larmurier I, Beaugerie L, et al. Impact of the increasing use of immunosuppressants in Crohn's disease on the need for intestinal surgery. Gut 2005;54(2):237-41.

41. Myrelid P, Olaison G, Sjödahl R, et al. Thiopurine therapy is associated with postoperative intra-abdominal septic complications in abdominal surgery for Crohn's disease. Dis Colon Rectum 2009; In press

42. Frøslie KF, Jahnsen J, Moum BA, et al. Mucosal healing in inflammatory bowel disease: results from a Norwegian population-based cohort. Gastroenterology 2007;133(2):412-22.

43. Markowitz J, Grancher K, Kohn N, et al. A multicenter trial of 6-mercaptopurine and prednisone in children with newly diagnosed Crohn's disease. Gastroenterology 2000;119(4):895-902.

44. Etchevers MJ, Aceituno M, Sans M. Are we giving azathioprine too late? The case for early immunomodulation in inflammatory bowel disease. World J Gastroenterol 2008;14(36):5512-18.

45. Treton X, Bouhnik Y, Mary JY, et al. Azathioprine withdrawal in patients with Crohn's disease maintained on prolonged remission: a high risk of relapse. Clin Gastroenterol Hepatol 2009;7(1):80-5.

46. Almer SH, Hjortswang H, Hindorf U. 6-Thioguanine therapy in Crohn's disease-observational data in Swedish patients. Dig Liver Dis 2009;41(3):194-200.

47. Teml A, Schaeffeler E, Herrlinger KR, et al. Thiopurine treatment in inflammatory bowel disease: clinical pharmacology and implication of pharmacogenetically guided dosing. Clin Pharmacokinet 2007;46(3):187-208.

48. Teml A, Schaeffeler E, Herrlinger KR, et al. Thiopurine treatment in inflammatory bowel disease: clinical pharmacology and implication of pharmacogenetically guided dosing. Clin Pharmacokinet 2007;46(3):187-208.

49. Pierik M, Rutgeerts P, Vlietinck R, et al. Pharmacogenetics in inflammatory bowel disease. World J Gastroenterol 2006;12(23):3657-67.

50. Ansari A, Hassan C, Duley J, et al. Thiopurine methyltransferase activity and the use of azathioprine in inflammatory bowel disease. Aliment Pharmacol Ther 2002;16(10):1743-50.

51. Hindorf U, Johansson M, Eriksson A, et al. Mercaptopurine treatment should be considered in azathioprine intolerant patients with inflammatory bowel disease. Aliment Pharmacol Ther 2009;29(6):654-61.

52. Ardizzone S, Bollani S, Manzionna G, et al. Comparison between methotrexate and azathioprine in the treatment of chronic active Crohn's disease: a randomised, investigator-blind study. Dig Liver Dis 2003;35(9):619-27.

53. Hassard PV, Vasiliauskas EA, Kam LY, et al. Efficacy of mycophenolate mofetil in patients failing 6-mercaptopurine or azathioprine therapy for Crohn's disease. Inflamm Bowel Dis 2000;6(1):16-20.

54. Tan T, Lawrance IC. Use of mycophenolate mofetil in inflammatory bowel disease. World J Gastroenterol 2009;15(13):1594-99. 
55. Baumgart DC, Wiedenmann B, Dignass AU. Rescue therapy with tacrolimus is effective in patients with severe and refractory inflammatory bowel disease. Aliment Pharmacol Ther 2003;17(10):1273-81.

56. Ierardi E, Principi M, Francavilla R, et al. Oral tacrolimus long-term therapy in patients with Crohn's disease and steroid resistance. Aliment Pharmacol Ther 2001;15(3):3717.

57. Feagan BG, Rochon J, Fedorak RN, et al. Methotrexate for the treatment of Crohn's disease. The North American Crohn's Study Group Investigators. N Engl J Med 1995;332(5):292-97.

58. Alfadhli AA, McDonald JW, Feagan BG. Methotrexate for induction of remission in refractory Crohn's disease. Cochrane Database Syst Rev 2005(1):CD003459.

59. Srinivasan R, Akobeng AK. Thalidomide and thalidomide analogues for induction of remission in Crohn's disease. Cochrane Database Syst Rev 2009(2):CD007350.

60. McDonald JW, Feagan BG, Jewell D, et al. Cyclosporine for induction of remission in Crohn's disease. Cochrane Database Syst Rev 2005(2):CD000297.

61. Reinisch W, Panes J, Lemann M, et al. A multicenter, randomized, double-blind trial of everolimus versus azathioprine and placebo to maintain steroid-induced remission in patients with moderate-to-severe active Crohn's disease. Am J Gastroenterol 2008;103(9):2284-92.

62. Vandeputte L, D'Haens G, Baert F, et al. Methotrexate in refractory Crohn's disease. Inflamm Bowel Dis 1999;5(1):11-15.

63. Korelitz BI. Is there any remaining role for methotrexate for Crohn's disease? Dig Liver Dis 2003;35(9):610-11.

64. van Dieren JM, Kuipers EJ, Samsom JN, et al. Revisiting the immunomodulators tacrolimus, methotrexate, and mycophenolate mofetil: their mechanisms of action and role in the treatment of IBD. Inflamm Bowel Dis 2006;12(4):311-27.

65. Akobeng AK, Stokkers PC. Thalidomide and thalidomide analogues for maintenance of remission in Crohn's disease. Cochrane Database Syst Rev 2009(2):CD007351.

66. Farmer RG, Hawk WA, Turnbull RB, Jr. Indications for surgery in Crohn's disease: analysis of 500 cases. Gastroenterology 1976;71(2):245-50.

67. Latchis KS, Rao CS, Colcock BP. The complications of enterocolitis. Am J Surg 1971;121(4):418-25.

68. Young S, Smith IS, O'Connor J, et al. Results of surgery for Crohn's disease in the Glasgow region, 1961-70. Br J Surg 1975;62(7):528-34.

69. Alves A, Panis Y, Bouhnik Y, et al. Risk factors for intra-abdominal septic complications after a first ileocecal resection for Crohn's disease: a multivariate analysis in 161 consecutive patients. Dis Colon Rectum 2007;50(3):331-36.

70. Post S, Betzler M, von Ditfurth B, et al. Risks of intestinal anastomoses in Crohn's disease. Ann Surg 1991;213(1):37-42.

71. Yamamoto T, Allan RN, Keighley MR. Risk factors for intra-abdominal sepsis after surgery in Crohn's disease. Dis Colon Rectum 2000;43(8):1141-5.

72. Aberra FN, Lewis JD, Hass D, et al. Corticosteroids and immunomodulators: postoperative infectious complication risk in inflammatory bowel disease patients. Gastroenterology 2003;125(2):320-27.

73. Lim M, Sagar P, Abdulgader A, et al. The impact of preoperative immunomodulation on pouch-related septic complications after ileal pouch-anal anastomosis. Dis Colon Rectum 2007;50(7):943-51.

74. Myrelid P, Olaison G, Sjödahl R, et al. Thiopurine therapy is associated with postoperative intra-abdominal septic complications in abdominal surgery for Crohn's 
disease. Dis Colon Rectum 2009;52(8):1387-94. doi:

10.1007/DCR.0b013e3181a7ba96

00003453-200908000-00005 [pii] [published Online First: 2009/07/21]

75. Tjandra JJ, Fazio VW, Milsom JW, et al. Omission of temporary diversion in restorative proctocolectomy--is it safe? Dis Colon Rectum 1993;36(11):1007-14.

76. Subramanian V, Saxena S, Kang JY, et al. Preoperative steroid use and risk of postoperative complications in patients with inflammatory bowel disease undergoing abdominal surgery. Am J Gastroenterol 2008;103(9):2373-81.

77. Bruewer M, Utech M, Rijcken EJ, et al. Preoperative steroid administration: effect on morbidity among patients undergoing intestinal bowel resection for Crohns disease. World J Surg 2003;27(12):1306-10.

78. Simi M, Leardi S, Minervini S, et al. Early complications after surgery for Crohn's disease. Neth J Surg 1990;42(4):105-9.

79. Alves A, Panis Y, Trancart D, et al. Factors associated with clinically significant anastomotic leakage after large bowel resection: multivariate analysis of 707 patients. World J Surg 2002;26(4):499-502.

80. Yamamoto T, Bain IM, Mylonakis E, et al. Stapled functional end-to-end anastomosis versus sutured end-to-end anastomosis after ileocolonic resection in Crohn disease. Scand J Gastroenterol 1999;34(7):708-13.

81. Schrock TR, Deveney CW, Dunphy JE. Factor contributing to leakage of colonic anastomoses. Ann Surg 1973;177(5):513-8.

82. Fasth S, Hellberg R, Hultén L, et al. Early complications after surgical treatment for Crohn's disease with particular reference to factors affecting their development. Acta Chir Scand 1980;146(7):519-26.

83. Golub R, Golub RW, Cantu R, Jr., et al. A multivariate analysis of factors contributing to leakage of intestinal anastomoses. J Am Coll Surg 1997;184(4):364-72.

84. Alexander-Williams J. Reducing the risk of Operation. In: Kumar D, Alexander-Williams J, eds. Crohn's Disease and Ulcerative Colitis - Surgical Management. London: Springer-Verlag 1993:51-66.

85. Schroll S, Sarlette A, Ahrens K, et al. Effects of azathioprine and its metabolites on repair mechanisms of the intestinal epithelium in vitro. Regul Pept 2005;131(1-3):1-11.

86. Karukonda SR, Flynn TC, Boh EE, et al. The effects of drugs on wound healing--part II. Specific classes of drugs and their effect on healing wounds. Int J Dermatol 2000;39(5):321-33.

87. Colombel JF, Loftus EV, Jr., Tremaine WJ, et al. Early postoperative complications are not increased in patients with Crohn's disease treated perioperatively with infliximab or immunosuppressive therapy. Am J Gastroenterol 2004;99(5):878-83.

88. Mahadevan U, Loftus EV, Jr., Tremaine WJ, et al. Azathioprine or 6-mercaptopurine before colectomy for ulcerative colitis is not associated with increased postoperative complications. Inflamm Bowel Dis 2002;8(5):311-16.

89. Mao EJ, Hazlewood GS, Kaplan GG, et al. Systematic review with meta-analysis: comparative efficacy of immunosuppressants and biologics for reducing hospitalisation and surgery in Crohn's disease and ulcerative colitis. Aliment Pharmacol Ther 2017;45(1):3-13. doi: 10.1111/apt.13847

90. Markowitz J. Can we change the natural history of Crohn's disease with early immunomodulation? Dig Dis 2014;32(4):345-50. doi: 10.1159/000358134

91. Chatu S, Subramanian V, Saxena S, et al. The role of thiopurines in reducing the need for surgical resection in Crohn's disease: a systematic review and meta-analysis. Am J Gastroenterol 2014;109(1):23-34; quiz 35. doi: 10.1038/ajg.2013.402 
92. Chhaya V, Pollok RC, Cecil E, et al. Impact of early thiopurines on surgery in 2770 children and young people diagnosed with inflammatory bowel disease: a national population-based study. Aliment Pharmacol Ther 2015;42(8):990-9. doi: 10.1111/apt.13361

93. Kariyawasam VC, Selinger CP, Katelaris PH, et al. Early use of thiopurines or methotrexate reduces major abdominal and perianal surgery in Crohn's disease. Inflamm Bowel Dis 2014;20(8):1382-90. doi: 10.1097/MIB.0000000000000119

94. Lakatos PL, Golovics PA, David G, et al. Has there been a change in the natural history of Crohn's disease? Surgical rates and medical management in a population-based inception cohort from Western Hungary between 1977-2009. Am J Gastroenterol 2012;107(4):579-88. doi: 10.1038/ajg.2011.448

95. Chatu S, Saxena S, Subramanian V, et al. The impact of timing and duration of thiopurine treatment on first intestinal resection in Crohn's disease: national UK populationbased study 1989-2010. Am J Gastroenterol 2014;109(3):409-16. doi: 10.1038/ajg.2013.462

96. Ramadas AV, Gunesh S, Thomas GA, et al. Natural history of Crohn's disease in a population-based cohort from Cardiff (1986-2003): a study of changes in medical treatment and surgical resection rates. Gut 2010;59(9):1200-6. doi:

10.1136/gut.2009.202101

gut.2009.202101 [pii] [published Online First: 2010/07/24]

97. Qiu Y, Chen BL, Mao R, et al. Early Thiopurines Versus Conventional Step-Care Therapy for Modifying the Disease Course of Early Crohn's Disease: A Tertiary Referral Center Cohort Study. Medicine (Baltimore) 2015;94(31):e1148. doi: 10.1097/MD.0000000000001148

98. Qiu Y, Chen BL, Mao R, et al. Endoscopy Assessment at 1-Year Identifies Long-Term Responders to Thiopurines Maintenance Therapy in Patients With Crohn's Disease. Medicine (Baltimore) 2015;94(31):e1204. doi: 10.1097/MD.0000000000001204

99. Alexakis C, Saxena S, Chhaya V, et al. Do Thiopurines Reduce the Risk of Surgery in Elderly Onset Inflammatory Bowel Disease? A 20-Year National Population-Based Cohort Study. Inflamm Bowel Dis 2017;23(4):672-80. doi: 10.1097/MIB.0000000000001031

100. Cosnes J, Bourrier A, Laharie D, et al. Early administration of azathioprine vs conventional management of Crohn's Disease: a randomized controlled trial. Gastroenterology 2013;145(4):758-65 e2; quiz e14-5. doi: 10.1053/j.gastro.2013.04.048

101. Panes J, Lopez-Sanroman A, Bermejo F, et al. Early azathioprine therapy is no more effective than placebo for newly diagnosed Crohn's disease. Gastroenterology 2013;145(4):766-74 e1. doi: 10.1053/j.gastro.2013.06.009

102. !!! INVALID CITATION !!! 89

103. Magro F, Rodrigues-Pinto E, Coelho R, et al. Is it possible to change phenotype progression in Crohn's disease in the era of immunomodulators? Predictive factors of phenotype progression. Am J Gastroenterol 2014;109(7):1026-36. doi: 10.1038/ajg.2014.97

104. Zhu Z, Mei Z, Guo Y, et al. Reduced Risk of Inflammatory Bowel Disease-associated Colorectal Neoplasia with Use of Thiopurines: a Systematic Review and Metaanalysis. J Crohns Colitis 2018;12(5):546-58. doi: 10.1093/ecco-jcc/jjy006

105. Rieder F, Reinisch W. Thiopurines and the natural course of Crohn's disease: did we finally find the right therapeutic target? Am J Gastroenterol 2014;109(7):1037-40. doi: 10.1038/ajg.2014.162 
106. Jones DW, Finlayson SR. Trends in surgery for Crohn's disease in the era of infliximab. Ann Surg 2010;252(2):307-12. doi: 10.1097/SLA.0b013e3181e61df5 [published Online First: 2010/06/30]

107. Thia KT, Sandborn WJ, Harmsen WS, et al. Risk factors associated with progression to intestinal complications of Crohn's disease in a population-based cohort. Gastroenterology 2010;139(4):1147-55. doi: 10.1053/j.gastro.2010.06.070

108. Gerdin L, Eriksson AS, Olaison G, et al. The Swedish Crohn Trial: A Prematurely Terminated Randomized Controlled Trial of Thiopurines or Open Surgery for Primary Treatment of Ileocaecal Crohn's Disease. J Crohns Colitis 2016;10(1):50-4. doi: 10.1093/ecco-jcc/jjv184 [published Online First: 2015/10/29]

109. Ponsioen CY, de Groof EJ, Eshuis EJ, et al. Laparoscopic ileocaecal resection versus infliximab for terminal ileitis in Crohn's disease: a randomised controlled, open-label, multicentre trial. Lancet Gastroenterol Hepatol 2017 doi: 10.1016/S24681253(17)30248-0

110. Iesalnieks I, Kilger A, Glass H, et al. Perforating Crohn's ileitis: delay of surgery is associated with inferior postoperative outcome. Inflamm Bowel Dis 2010;16(12):2125-30. doi: 10.1002/ibd.21303 [published Online First: 2010/09/18]

111. de Groof EJ, Carbonnel F, Buskens CJ, et al. Abdominal abscess in Crohn's disease: multidisciplinary management. Dig Dis 2014;32 Suppl 1:103-9. doi: $10.1159 / 000367859$

112. Dignass A, Van Assche G, Lindsay JO, et al. The second European evidence-based Consensus on the diagnosis and management of Crohn's disease: Current management. J Crohns Colitis 2010;4(1):28-62. doi: 10.1016/j.crohns.2009.12.002

S1873-9946(09)00145-7 [pii] [published Online First: 2010/12/03]

113. Myrelid P, Svärm S, Andersson P, et al. Azathioprine as a postoperative prophylaxis reduces symptoms in aggressive Crohn's disease. Scand J Gastroenterol 2006;41(10):1190-5.

114. Tay GS, Binion DG, Eastwood D, et al. Multivariate analysis suggests improved perioperative outcome in Crohn's disease patients receiving immunomodulator therapy after segmental resection and/or strictureplasty. Surgery 2003;134(4):565-72; discussion 72-3. doi: 10.1016/S0039

S0039606003002988 [pii] [published Online First: 2003/11/08]

115. Selvasekar CR, Cima RR, Larson DW, et al. Effect of infliximab on short-term complications in patients undergoing operation for chronic ulcerative colitis. $J \mathrm{Am}$ Coll Surg 2007;204(5):956-62.

116. Sandborn W, Sutherland L, Pearson D, et al. Azathioprine or 6-mercaptopurine for induction of remission in Crohn's disease. Cochrane Database Syst Rev 2002(2)

117. Kanazawa A, Yamana T, Okamoto K, et al. Risk factors for postoperative intraabdominal septic complications after bowel resection in patients with Crohn's disease. Dis Colon Rectum 2012;55(9):957-62. doi: 10.1097/DCR.0b013e3182617716

118. Oresland T, Bemelman WA, Sampietro GM, et al. European evidence based consensus on surgery for ulcerative colitis. J Crohns Colitis 2015;9(1):4-25. doi: 10.1016/j.crohns.2014.08.012

119. Mantzoros I, Kanellos I, Demetriades H, et al. Effects of steroid on the healing of colonic anastomoses in the rat. Tech Coloproctol 2004;8 Suppl 1:180-83.

120. Polat A, Nayci A, Polat G, et al. Dexamethasone down-regulates endothelial expression of intercellular adhesion molecule and impairs the healing of bowel anastomoses. Eur J Surg 2002;168(8-9):500-6.

121. Del Rio JV, Beck DE, Opelka FG. Chronic perioperative steroids and colonic anastomotic healing in rats. J Surg Res 1996;66(2):138-42. 
122. Furst MB, Stromberg BV, Blatchford GJ, et al. Colonic anastomoses: bursting strength after corticosteroid treatment. Dis Colon Rectum 1994;37(1):12-5.

123. Roberts AB, Sporn MB. Physiological actions and clinical applications of transforming growth factor-beta (TGF-beta). Growth Factors 1993;8(1):1-9.

124. Wicke C, Halliday B, Allen D, et al. Effects of steroids and retinoids on wound healing. Arch Surg 2000;135(11):1265-70.

125. Lima O, Cooper JD, Peters WJ, et al. Effects of methylprednisolone and azathioprine on bronchial healing following lung autotransplantation. J Thorac Cardiovasc Surg 1981;82(2):211-5.

126. Myrelid P, Salim SY, Darby T, et al. Effects of anti-inflammatory therapy on bursting pressure of colonic anastomosis in murine dextran sulfate sodium induced colitis. Scand J Gastroenterol 2015:1-11. doi: 10.3109/00365521.2014.964760

127. Stolzenburg T, Ljungmann K, Christensen $\mathrm{H}$. The effect of azathioprine on anastomotic healing: an experimental study in rats. Dis Colon Rectum 2007;50(12):2203-8.

128. Schäffer M, Fuchs N, Volker J, et al. Differential effect of tacrolimus on dermal and intestinal wound healing. J Invest Surg 2005;18(2):71-9.

129. Schäffer MR, Fuchs N, Proksch B, et al. Tacrolimus impairs wound healing: a possible role of decreased nitric oxide synthesis. Transplantation 1998;65(6):813-8.

130. Petri JB, Schurk S, Gebauer S, et al. Cyclosporine A delays wound healing and apoptosis and suppresses activin beta-A expression in rats. Eur J Dermatol 1998;8(2):104-13.

131. Fishel R, Barbul A, Wasserkrug HL, et al. Cyclosporine A impairs wound healing in rats. J Surg Res 1983;34(6):572-5.

132. Zeeh J, Inglin R, Baumann G, et al. Mycophenolate mofetil impairs healing of left-sided colon anastomoses. Transplantation 2001;71(10):1429-35.

133. Egger B, Tolmos J, Procaccino F, et al. Keratinocyte growth factor promotes healing of left-sided colon anastomoses. Am J Surg 1998;176(1):18-24.

134. Zeeh JM, Procaccino F, Hoffmann P, et al. Keratinocyte growth factor ameliorates mucosal injury in an experimental model of colitis in rats. Gastroenterology 1996;110(4):1077-83.

135. Egger B, Procaccino F, Sarosi I, et al. Keratinocyte growth factor ameliorates dextran sodium sulfate colitis in mice. Dig Dis Sci 1999;44(4):836-44.

136. Di Sebastiano P, di Mola FF, Artese L, et al. Beneficial effects of Batimastat (BB-94), a matrix metalloproteinase inhibitor, in rat experimental colitis. Digestion 2001;63(4):234-39.

137. Medina C, Santana A, Paz MC, et al. Matrix metalloproteinase-9 modulates intestinal injury in rats with transmural colitis. J Leukoc Biol 2006;79(5):954-62.

138. Syk I, Agren MS, Adawi D, et al. Inhibition of matrix metalloproteinases enhances breaking strength of colonic anastomoses in an experimental model. Br J Surg 2001;88(2):228-34.

139. Kiyama T, Onda M, Tokunaga A, et al. Effect of matrix metalloproteinase inhibition on colonic anastomotic healing in rats. J Gastrointest Surg 2001;5(3):303-11.

140. Myrelid P, Marti-Gallostra M, Ashraf S, et al. Complications in surgery for Crohn's disease after preoperative antitumour necrosis factor therapy. Br J Surg 2014;101(5):539-45. doi: 10.1002/bjs.9439

141. Smedh K, Andersson M, Johansson H, et al. Preoperative management is more important than choice of sutured or stapled anastomosis in Crohn's disease. Eur J Surg 2002;168(3):154-7. 
142. Myrelid P, Soderholm JD, Olaison G, et al. Split stoma in resectional surgery of highrisk patients with ileocolonic Crohn's disease. Colorectal Dis 2012;14(2):188-93. doi: 10.1111/j.1463-1318.2011.02578.x [published Online First: 2011/06/22]

143. Bernell O, Lapidus A, Hellers G. Risk factors for surgery and postoperative recurrence in Crohn's disease. Ann Surg 2000;231(1):38-45.

144. Farmer RG, Whelan G, Fazio VW. Long-term follow-up of patients with Crohn's disease. Relationship between the clinical pattern and prognosis. Gastroenterology 1985;88(6):1818-25.

145. Vester-Andersen MK, Prosberg MV, Jess T, et al. Disease course and surgery rates in inflammatory bowel disease: a population-based, 7-year follow-up study in the era of immunomodulating therapy. Am J Gastroenterol 2014;109(5):705-14. doi: 10.1038/ajg.2014.45

146. Olaison G, Smedh K, Sjödahl R. Natural course of Crohn's disease after ileocolic resection: endoscopically visualised ileal ulcers preceding symptoms. Gut 1992;33(3):331-35.

147. Riss S, Schuster I, Papay P, et al. Surgical recurrence after primary ileocolic resection for Crohn's disease. Tech Coloproctol 2014;18(4):365-71. doi: 10.1007/s10151-0131061-4

148. Renna S, Camma C, Modesto I, et al. Meta-analysis of the placebo rates of clinical relapse and severe endoscopic recurrence in postoperative Crohn's disease. Gastroenterology 2008;135(5):1500-9. doi: 10.1053/j.gastro.2008.07.066

149. Ferrante M, Papamichael K, Duricova D, et al. Systematic versus Endoscopy-driven Treatment with Azathioprine to Prevent Postoperative Ileal Crohn's Disease Recurrence. J Crohns Colitis 2015;9(8):617-24. doi: 10.1093/ecco-jcc/jjv076

150. Hellers G, Cortot A, Jewell D, et al. Oral budesonide for prevention of postsurgical recurrence in Crohn's disease. The IOIBD Budesonide Study Group. Gastroenterology 1999;116(2):294-300.

151. D'Haens GR, Vermeire S, Van Assche G, et al. Therapy of metronidazole with azathioprine to prevent postoperative recurrence of Crohn's disease: a controlled randomized trial. Gastroenterology 2008;135(4):1123-29.

152. Lochs H, Mayer M, Fleig WE, et al. Prophylaxis of postoperative relapse in Crohn's disease with mesalamine: European Cooperative Crohn's Disease Study VI [see comments]. Gastroenterology 2000;118(2):264-73.

153. Hanauer SB, Korelitz BI, Rutgeerts P, et al. Postoperative maintenance of Crohn's disease remission with 6-mercaptopurine, mesalamine, or placebo: a 2-year trial. Gastroenterology 2004;127(3):723-9.

154. Rutgeerts P, Geboes K, Vantrappen G, et al. Predictability of the postoperative course of Crohn's disease. Gastroenterology 1990;99(4):956-63.

155. Mowat C, Arnott I, Cahill A, et al. Mercaptopurine versus placebo to prevent recurrence of Crohn's disease after surgical resection (TOPPIC): a multicentre, double-blind, randomised controlled trial. Lancet Gastroenterol Hepatol 2016;1(4):273-82. doi: 10.1016/S2468-1253(16)30078-4

156. McLeod RS, Wolff BG, Steinhart AH, et al. Prophylactic mesalamine treatment decreases postoperative recurrence of Crohn's disease. Gastroenterology 1995;109(2):404-13.

157. Borley NR, Mortensen NJ, Jewell DP. Preventing postoperative recurrence of Crohn's disease. Br J Surg 1997;84(11):1493-502.

158. Michelassi F, Balestracci T, Chappell R, et al. Primary and recurrent Crohn's disease. Experience with 1379 patients. Ann Surg 1991;214(3):230-8; discussion 38-40. 
159. Myrelid P, Svarm S, Andersson P, et al. Azathioprine as a postoperative prophylaxis reduces symptoms in aggressive Crohn's disease. Scand J Gastroenterol 2006;41(10):1190-5. doi: 10.1080/00365520600587378

160. Domenech E, Garcia V, Iborra M, et al. Incidence and Management of Recurrence in Patients with Crohn's Disease Who Have Undergone Intestinal Resection: The Practicrohn Study. Inflamm Bowel Dis 2017;23(10):1840-46. doi: 10.1097/MIB.0000000000001180

161. Papay P, Reinisch W, Ho E, et al. The impact of thiopurines on the risk of surgical recurrence in patients with Crohn's disease after first intestinal surgery. Am J Gastroenterol 2010;105(5):1158-64. doi: 10.1038/ajg.2009.673

162. van Loo ES, Vosseberg NW, van der Heide F, et al. Thiopurines are associated with a reduction in surgical re-resections in patients with Crohn's disease: a long-term follow-up study in a regional and academic cohort. Inflamm Bowel Dis 2013;19(13):2801-8. doi: 10.1097/01.MIB.0000435758.97952.a8

163. Li Y, Zhu W, Zuo L, et al. Frequency and risk factors of postoperative recurrence of Crohn's disease after intestinal resection in the Chinese population. $J$ Gastrointest Surg 2012;16(8):1539-47. doi: 10.1007/s11605-012-1902-x

164. Orlando A, Mocciaro F, Renna S, et al. Early post-operative endoscopic recurrence in Crohn's disease patients: data from an Italian Group for the study of inflammatory bowel disease (IG-IBD) study on a large prospective multicenter cohort. J Crohns Colitis 2014;8(10):1217-21. doi: 10.1016/j.crohns.2014.02.010

165. De Cruz P, Kamm MA, Hamilton AL, et al. Crohn's disease management after intestinal resection: a randomised trial. Lancet 2015;385(9976):1406-17. doi: 10.1016/S01406736(14)61908-5

166. Reese GE, Nanidis T, Borysiewicz C, et al. The effect of smoking after surgery for Crohn's disease: a meta-analysis of observational studies. Int J Colorectal Dis 2008;23(12):1213-21.

167. Yamamoto T, Watanabe T. Strategies for the prevention of postoperative recurrence of Crohn's disease. Colorectal Dis 2013;15(12):1471-80. doi: 10.1111/codi.12326

168. Gionchetti P, Dignass A, Danese S, et al. 3rd European Evidence-based Consensus on the Diagnosis and Management of Crohn's Disease 2016: Part 2: Surgical Management and Special Situations. J Crohns Colitis 2017;11(2):135-49. doi: 10.1093/ecco-jcc/jjw169

169. Simillis C, Yamamoto T, Reese GE, et al. A meta-analysis comparing incidence of recurrence and indication for reoperation after surgery for perforating versus nonperforating Crohn's disease. Am J Gastroenterol 2008;103(1):196-205. doi: 10.1111/j.1572-0241.2007.01548.x

170. Simillis C, Jacovides M, Reese GE, et al. Meta-analysis of the role of granulomas in the recurrence of Crohn disease. Dis Colon Rectum 2010;53(2):177-85. doi: 10.1007/DCR.0b013e3181b7bfb0

00003453-201002000-00011 [pii] [published Online First: 2010/01/21]

171. Ferrante M, de Hertogh G, Hlavaty T, et al. The value of myenteric plexitis to predict early postoperative Crohn's disease recurrence. Gastroenterology 2006;130(6):1595606. doi: S0016-5085(06)00336-2 [pii]

10.1053/j.gastro.2006.02.025 [published Online First: 2006/05/16]

172. Sokol H, Polin V, Lavergne-Slove A, et al. Plexitis as a predictive factor of early postoperative clinical recurrence in Crohn's disease. Gut 2009;58(9):1218-25. doi: 10.1136/gut.2009.177782

gut.2009.177782 [pii] [published Online First: 2009/07/25] 
173. Borley NR, Mortensen NJ, Chaudry MA, et al. Recurrence after abdominal surgery for Crohn's disease: relationship to disease site and surgical procedure. Dis Colon Rectum 2002;45(3):377-83.

174. Reese GE, Purkayastha S, Tilney HS, et al. Strictureplasty vs resection in small bowel Crohn's disease: an evaluation of short-term outcomes and recurrence. Colorectal Dis 2007;9(8):686-94.

175. Domenech E, Manosa M, Bernal I, et al. Impact of azathioprine on the prevention of postoperative Crohn's disease recurrence: results of a prospective, observational, longterm follow-up study. Inflamm Bowel Dis 2008;14(4):508-13. doi: 10.1002/ibd.20359

176. Ardizzone S, Maconi G, Sampietro GM, et al. Azathioprine and mesalamine for prevention of relapse after conservative surgery for Crohn's disease. Gastroenterology 2004;127(3):730-40.

177. Herfarth H, Tjaden C, Lukas M, et al. Adverse events in clinical trials with azathioprine and mesalamine for prevention of postoperative recurrence of Crohn's disease. Gut 2006;55(10):1525-6. doi: 55/10/1525 [pii] [published Online First: 2006/09/13]

178. Peyrin-Biroulet L, Deltenre P, Ardizzone S, et al. Azathioprine and 6-mercaptopurine for the prevention of postoperative recurrence in Crohn's disease: a meta-analysis. Am J Gastroenterol 2009;104(8):2089-96. doi: ajg2009301 [pii]

10.1038/ajg.2009.301 [published Online First: 2009/07/02]

179. Reinisch W, Angelberger S, Petritsch W, et al. Azathioprine versus mesalazine for prevention of postoperative clinical recurrence in patients with Crohn's disease with endoscopic recurrence: efficacy and safety results of a randomised, double-blind, double-dummy, multicentre trial. Gut 2010;59(6):752-9. doi: 10.1136/gut.2009.194159

180. Savarino E, Bodini G, Dulbecco P, et al. Adalimumab is more effective than azathioprine and mesalamine at preventing postoperative recurrence of Crohn's disease: a randomized controlled trial. Am J Gastroenterol 2013;108(11):1731-42. doi: 10.1038/ajg.2013.287

181. Armuzzi A, Felice C, Papa A, et al. Prevention of postoperative recurrence with azathioprine or infliximab in patients with Crohn's disease: an open-label pilot study. J Crohns Colitis 2013;7(12):e623-9. doi: 10.1016/j.crohns.2013.04.020

182. Gordon M, Taylor K, Akobeng AK, et al. Azathioprine and 6-mercaptopurine for maintenance of surgically-induced remission in Crohn's disease. Cochrane Database Syst Rev 2014(8):CD010233. doi: 10.1002/14651858.CD010233.pub2

183. Lopez-Sanroman A, Vera-Mendoza I, Domenech E, et al. Adalimumab vs Azathioprine in the Prevention of Postoperative Crohn's Disease Recurrence. A GETECCU Randomised Trial. J Crohns Colitis 2017;11(11):1293-301. doi: 10.1093/eccojcc/jjx051

184. Hansen LF, Jakobsen C, Paerregaard A, et al. Surgery and postoperative recurrence in children with Crohn disease. J Pediatr Gastroenterol Nutr 2015;60(3):347-51. doi: 10.1097/MPG.0000000000000616

185. Splawski JB, Pffefferkorn MD, Schaefer ME, et al. NASPGHAN Clinical Report on Postoperative Recurrence in Pediatric Crohn Disease. J Pediatr Gastroenterol Nutr 2017;65(4):475-86. doi: 10.1097/MPG.0000000000001606

186. Baldassano RN, Han PD, Jeshion WC, et al. Pediatric Crohn's disease: risk factors for postoperative recurrence. Am J Gastroenterol 2001;96(7):2169-76. doi: 10.1111/j.1572-0241.2001.03876.x

187. Bordeianou L, Stein SL, Ho VP, et al. Immediate versus tailored prophylaxis to prevent symptomatic recurrences after surgery for ileocecal Crohn's disease? Surgery 2011;149(1):72-8. doi: 10.1016/j.surg.2010.03.009 
188. Guo Z, Cai C, Liu R, et al. Immediate prophylactic versus endoscopic or symptomatic driven azathioprine treatment to prevent surgical recurrence after intestinal resection in Crohn's disease. Colorect Dis 2018(In press)

189. Moran GW, Dubeau MF, Kaplan GG, et al. Clinical predictors of thiopurine-related adverse events in Crohn's disease. World J Gastroenterol 2015;21(25):7795-804. doi: 10.3748/wjg.v21.i25.7795

190. Ananthakrishnan AN, Hur C, Juillerat P, et al. Strategies for the prevention of postoperative recurrence in Crohn's disease: results of a decision analysis. Am J Gastroenterol 2011;106(11):2009-17. doi: 10.1038/ajg.2011.237

191. Doherty GA, Miksad RA, Cheifetz AS, et al. Comparative cost-effectiveness of strategies to prevent postoperative clinical recurrence of Crohn's disease. Inflamm Bowel Dis 2012;18(9):1608-16. doi: 10.1002/ibd.21904

192. Bordeianou L. In flux on infliximab: Conflicting studies on surgical outcomes. Inflamm Bowel Dis 2009

193. Scarpa M, Ruffolo C, Bertin E, et al. Surgical predictors of recurrence of Crohn's disease after ileocolonic resection. Int J Colorectal Dis 2007;22(9):1061-69.

194. Welsch T, Hinz U, Loffler T, et al. Early re-laparotomy for post-operative complications is a significant risk factor for recurrence after ileocaecal resection for Crohn's disease. Int J Colorectal Dis 2007;22(9):1043-49.

195. Sartini A, Scaioli E, Belluzzi A. Is Early Endoscopy-Based Therapy the Best Strategy to Prevent All Crohn's Disease Postoperative Recurrence? Gastroenterology 2016;151(5):1040-41. doi: 10.1053/j.gastro.2016.08.058 